\title{
As ações do Estado na produção do território na cidade de Feira de Santana.
}

\author{
Ramile de Jesus Oliveira, UEFS \\ ra.mile@hotmail.com
}

Palavras-Chave: Cidade, paisagem, urbanização.

\section{INTRODUÇÃO}

Entre os anos 1950 e 1960 do século XX, Feira de Santana se torna alvo da politica de desenvolvimento econômico da nação brasileira, onde um dos principais objetivos era o desenvolvimento do país, o seu crescimento econômico e a modernização das cidades, incentivar o processo de industrialização foi uma das estratégias politicas da época. A partir de então, é possível perceber uma série de transformações socioeconômicas e urbanas ocorridas na cidade de Feira de Santana, que vão além do seu crescimento populacional, dentre estas podemos citar o seu crescimento territorial, o desenvolvimento do comércio, a instalação de indústrias, a expansão urbana da cidade, a organização e reorganização do sistema de transportes público e a construção de novos eixos viários, essas transformações possibilitaram uma nova dinâmica espacial, paisagística e consequentemente no cotidiano. A partir do ano de 2007, houve um crescimento significativo das ações estatais na produção e modernização da cidade de Feira de Santana, principalmente no que se refere à abertura de viadutos e novas avenidas, avenidas como Nóide Cerqueira, Ayrton Senna e Fraga Maia foram construções recentes e que trazem em sua arquitetura, elementos que caracterizam a adoção de um ideal modernizador para a cidade, pois estas avenidas em Feira de Santana tem em comum a presença cada vez maior de equipamentos que representam modernidades, estas modernidades trazem consigo um ideal de cidade acolhedora e confortável, logo a inserção de espaços de lazer e que proporcionem a sensação de bem estar tem sido introduzidos cada vez mais na sua paisagem urbana, ou seja, nestas avenidas, a introdução de equipamentos lúdicos, que estimulem bem estar e prazer como: arborização ao longo da avenida, espaços para prática de esportes, praças, pista para ciclista e pedestres tem sido cada vez mais comum e possibilitam um caráter modernizador e atraente à cidade. Dessa forma, para esta pesquisa convém destacar as ações estatais que possibilitaram transformações no espaço urbano e na sua expansão física, principalmente referentes ao sistema viário e de transportes público da cidade de Feira de Santana. Para isso, elencou-se como objetivo central: Estudar as ações do Estado na produção do território na cidade de Feira de Santana/Bahia.

\section{Material e Métodos ou Metodologia}

Para o desenvolvimento deste trabalho, incialmente foi feito um levantamento bibliográfico para definição da base teórica e aprofundamento dos conceitos de cidade, paisagem e urbanização. Em seguida, foi feita uma coleta de dados e informações através de sites dos órgãos municipais e jornais públicos. Após a pesquisa bibliográfica foi realizado trabalhos de campo nas áreas de estudo, sendo estas: os terminais de transbordo e as avenidas Fraga Maia, Nóide Cerqueira e Ayrton Senna, foram feitos imagens e a realização de entrevistas com moradores locais e transeuntes encontrados na comunidade, com os 
dados obtidos nesse trabalho de campo, iniciou-se um processo de avaliação dos dados obtidos e produção de gráficos e tabelas sobre a área de estudo. Por final, foi feito a elaboração do relatório final da pesquisa.

\section{Resultados e/ou Discussão}

O município de Feira de Santana considerada a segunda maior cidade do Estado da Bahia como uma cidade de médio porte, tem passado por um constante processo de urbanização, sendo a figura do Estado um dos principais agentes produtores do espaço. Nos ultimos doze anos (entre 2002 a 2016), a cidade tem passado por sucessivas transformações em seus eixos viários e no seu sistema de transporte público. A implantação do atual sistema de transporte público de Feira de Santana em 2005, como pode-se ver nas figuras 1 e 2 de um dos terminais fixos de transbordo aliado à abertura das avenidas Nóide Cerqueira em 2014, Fraga Maia em 2015 e Ayrton Senna em 2012 como se observa nas figuras 3, 4 e 5, foram intervenções entre Estado e iniciativa privada que possibilitaram mudanças significativas no cotidiano e na mobilidade espacial da cidade, além de permitir o a expansão urbana de áreas consideradas pouco ocupadas em Feira de Santana.

\section{Figura 1: Entrada do terminal Central}

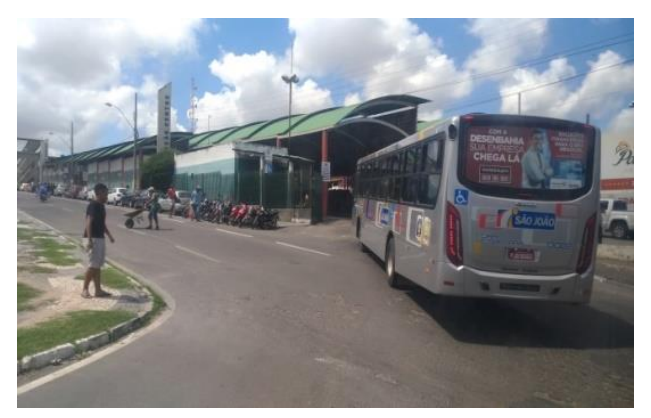

Fonte: Ramile Oliveira, 2017

\section{Figura2: Interior do Terminal Central}

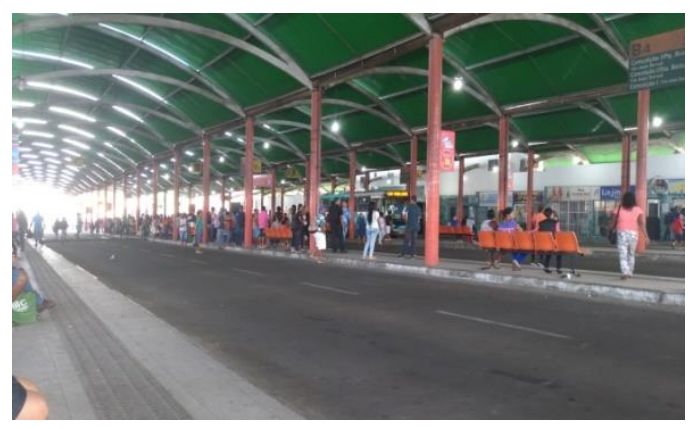

Figura 3. Avenida Nóide Ferreira de Cerqueira em Feira de Santana - Bahia

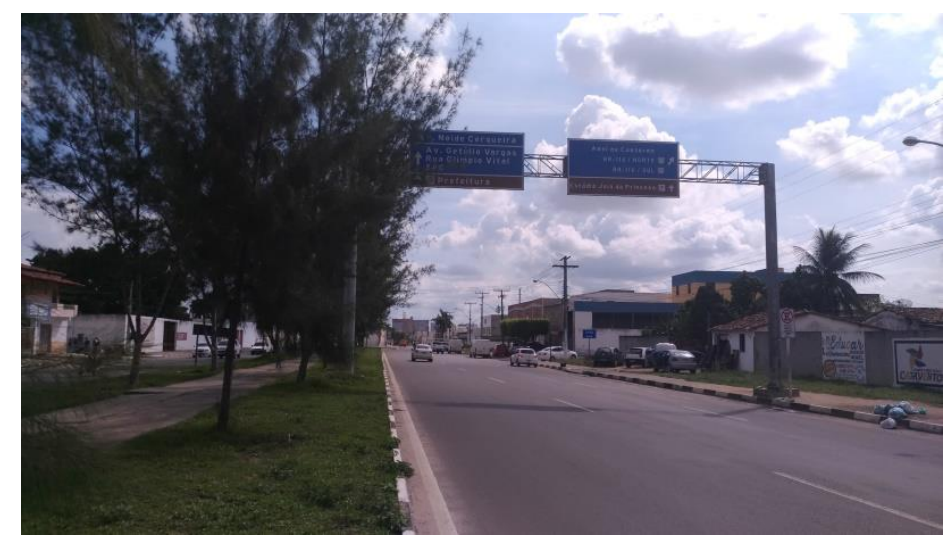

Fonte: Ramile Oliveira, 2017 
Figura 4. Avenida Fraga Maia em Feira de Santana - Bahia

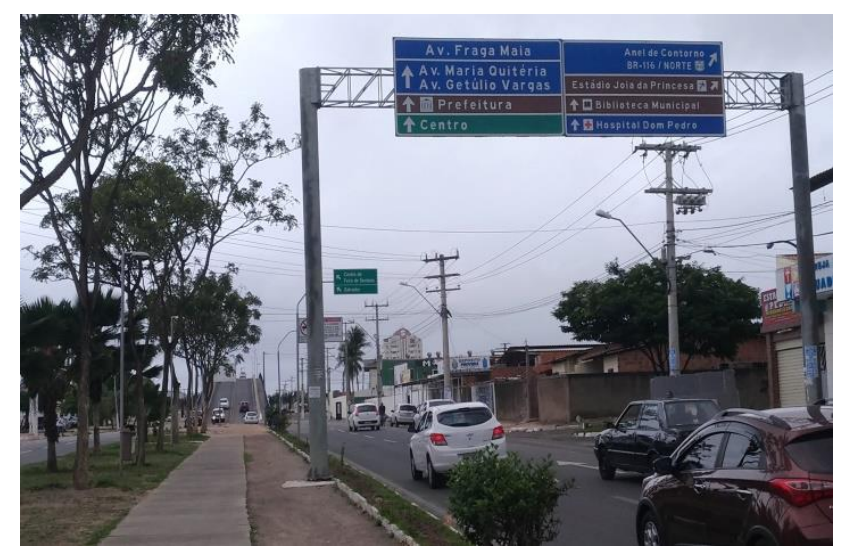

Fonte: Ramile Oliveira, 2017

Figura 5. Avenida Ayrton Sena da Silva em Feira de Santana - Bahia

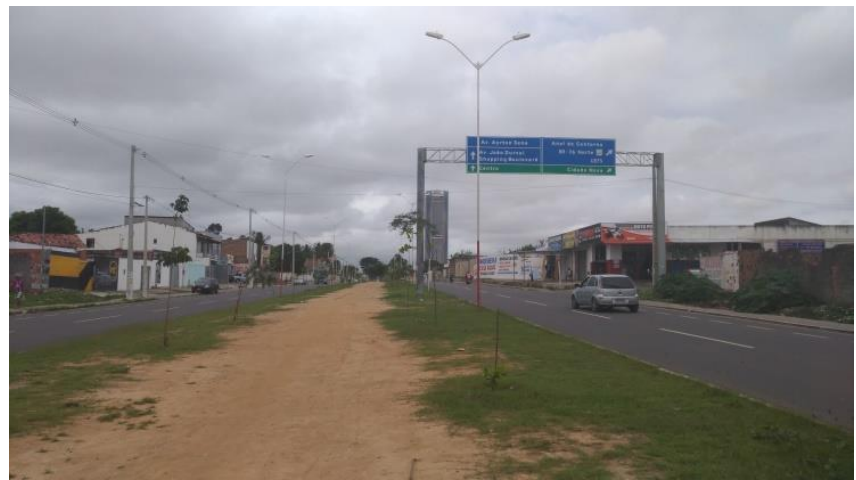

Fonte: Ramile Oliveira, 2017

Estas ações do Estado na cidade demonstra um processo de modernização urbana, pois as avenidas seguem uma arquitetura semelhante com canteiros para pedestres e ciclistas, areas arborizadas e espaços de lazer, reforçando o ideal de cidade confortável e 
atraente e demonstrando também o continuo reordenamento territorial do município, pois se a cidade cresce, modifica-se seu contornos e entornos.

\section{Considerações Finais}

A cidade cresce, mas nem sempre esse crescimento está ligado à satisfação de sua comunidade, inúmeras questões desde a construção de obras públicas como avenidas, vias até ao sistema de transportes coletivos ou questões que dizem respeito diretamente ao bem estar e a qualidade de vida da população por vezes são negligenciadas quando o Estado intervém no espaço urbano.

Dessa forma, acreditamos impassivelmente na necessidade da população nas discussões que dizem respeito ao seu cotidiano e à produção da cidade, nas deliberações e nos espaços de decisão como forma de garantir um espaço produzido por aqueles que o vivem e uma cidade justa, igualitária e acessível para todos.

\section{Referências}

AGKF - Engenharia e Consultoria LTDA. Estudo de Racionalização e Modernização do Sistema de Transportes Coletivos de Feira de Santana. 2006. Feira de Santana, Bahia;

Bus rapid transit - BRT de transporte de passageiros da cidade de feira de Santana. Projeto executivo março / 2014

FEIRA DE SANTANA. LEI Nº. 3473, de 24 de Setembro 2014. Dispõe sobre nova redação para o Código de Obras e Edificações do município de Feira de Santana, revogando integralmente a lei nº 632/1969, e dá outras providências.

Feira de Santana. lei complementar $n^{\circ} .86$ de 24 de setembro 2014. altera, modifica, amplia e dá nova redação à lei $n^{\circ}$ 1615/92, que institui a lei do ordenamento do uso e da ocupação do solo na área urbana do município de Feira de Santana e revoga a lei complementar $n^{\circ} 46$, de 19 de agosto de 2010, que dispõe sobre o sistema viário das áreas de expansão urbana da cidade de Feira de Santana.

FERRAZ, Antônio Clóvis “Coca” P.; TORRES, Isaac G. E. Transporte Público Urbano. São Carlos - SP. Rima, 2004;

Instituto Brasileiro de Geografia e Estatistica - 2010

Superintendência de Estudos Econômicos e Sociais da Bahia, 2010

Secretaria Municipal de Transporte e Transito. Feira de Santana. 2009;

SILVA, Alex de Souza. A influência do Centro Industrial do Subaé (CIS) no pro cesso de urbanização do bairro do Tomba: um estudo de caso do município de Feira de Santana. 177. F.. il 2010. Dissertação Mestrado UNIFACS. 